\title{
Explanation of valuation criteria based on maturity level of Knowledge management
}

\author{
Professor Dr. Sorush Niknamian \\ Board Member of Weston A Price Foundation, Washington Dc, USA \\ E-mail: so.niknamian@gmail.com
}

\begin{abstract}
In This study explains valuation criteria Based on the maturity level of knowledge management in executive agencies Khuzestan province in order to provide a local model is studied. In this study, two questionnaires of valuation criteria (51questions, Cronbach's $\alpha=0.94$ ), and maturity level of knowledge management (98 questions, Cronbach's $\alpha=0.93$ ) have been used. The statistical population involves people from administrative staff of Khuzestan province, which 382 individuals were selected as the statistical sample by using Cochran's formula Spss 22 and Amos 22 software were used to analyze the data. The study results shoed that valuation criteria involved 17 variables, among which the technical index variable enjoyed the highest ranking mean (11.99), and the maintainability variable benefited from the lowest ranking mean (79.6) among the other variables in the statistical population of the research. In maturity level of knowledge management included 13 variables, which, generally it can said that this variable enjoyed the benefit of being more than satisfactory level. Also, the results showed that there was a significant relationship between the valuation criteria, and the maturity level of knowledge management.
\end{abstract}

Keywords: valuation criteria, knowledge management and maturity level of Knowledge management.

\section{Introduction:}

Today, with the increasing importance of knowledge management in the success of business units, this concept is increasingly being used in leading organizations to create sustainable competitive advantage. However, there is still no comprehensive approach to determining the current status of organizations in the field of knowledge management and, moreover, what needs to be done to achieve a desirable position, therefore Continuous improvement is based on evolutionary and step-by-step development(Kochikar,2005), That From these evolutionary stages of knowledge management, which evolves over time, is the concept of knowledge management maturity, in other words, it requires knowledge management to mature, from a harsh state to an interdisciplinary function that is firmly established in the organization-based Has been turned (Ehms and Langen,2002). To fill this gap in recent years, by relevant experts, models have been proposed inspired by puberty models called knowledge management maturity models. The maturity model of knowledge management is a structured approach to implementing knowledge management (Kuriakose et al, 2010). In the field of knowledge management, different maturity models have been introduced(Oliva,2014), But The lack of appropriate models for evaluating the extent of development and maturity of organizations from the perspective of knowledge management and limited practical evidence is available in assessing the impact and effectiveness of maturity models of knowledge management, This necessitates the need for a comprehensive model for assessing the maturity of knowledge management in an organization. Assessing the degree of growth and maturity of knowledge management has to be done with regard to the organizational culture and existing management systems or technological requirements, and it also provides solutions to control some of the common problems of knowledge management such as information, knowledge acquisition complexity 
and knowledge storage (Kuriakose, 2011). The presence of various models knowledge management maturity, and the results from implementing them in many of the official organizations all over the world, indicate the importance of this concept in the managements. Therefore, it is a need to represent a comprehensive model of knowledge management maturity for the guidance and assessment of the development of knowledge management (Hsieh et al, 2009, 4087). According to the researchers, various models have been offered for the knowledge management maturity, but most of them lack generality (TeahPee \& Kankanhalli, 2006, 401; Ehms and Langen, 2002,1), and have not been experimentally tested, and that many of the models are generalizations (Ying-Hsun and Seng-Cho, 2005,2 ). On this regard, many of the knowledge management maturity models suffer from weaknesses, which are necessary to be understood. But also, we should regard that it is necessary for the organizations to assess its establishment feasibility prior to the creation and implementation of knowledge management maturity system. Therefore, in this respect, in the official organizations, the identification and specification of system valuation criteria, i.e. assessment of system value by using three major indices of feasibility, strategic index, and design index (Zahedi, 2012:338), and their prioritization which belong to the efficient key factors for the proper adoption and implementation of knowledge management system should be studied and investigated in order to provide the necessary background for implementing knowledge management. So, in this study, we specify the valuation criteria based on maturity level of knowledge management in the administrative organizations of Khuzestan province, in order to represent a local model.

\section{Review of the literature}

\section{Maturity level of knowledge management}

According to the definition by American center for quality and Efficiency, the knowledge management is a strategy which aims to provide plain knowledge for the individual in the proper time. Also, the knowledge management is a kind of strategic management involving individuals, and giving knowledge together with the backgrounds, and related information in the organization, by using technology, and its processes (Souresh and Mahesh, 2006, 14). According to the previous studies, benefitting from knowledge and the knowledge management has become a grand condition for continuing the life of dynamic and innovative organizations; Even, the ability to compete in the markets, and transactions are related to the acquisition, development and implementation of individual and organizational knowledge (Chen and Huang, 2012, 262). The maturity level is a definite evolutionary condition for a process which is at maturity, to become successful (Zakeri, 2016, 188); and, the knowledge management maturity model is a structured approach for implementing knowledge management (Kuriakose et al, 2011,2). According to Wibowo and Waluyo (2015), the knowledge management maturity is guidance or criteria for assessing the organizational condition in the field of knowledge management. In the review The factors influencing the maturity of knowledge management and its critical success factors have been a lot of studies and researchers have introduced important findings in the implementation and promotion of the position of knowledge management, but knowledge management systems are complex and the multiplicity of factors and challenges It has made it difficult to predict the behavior of the system. Therefore, in order to achieve a general understanding of the behavior of the system, one must examine how the factors affect each other over time and the feedback relationships between them. These relationships should demonstrate how the system functions over time (Rodrigues \& Martis, 2004). According to Serenko et al., (2015), which examined the use of the knowledge management maturity model in credit unions, The Availability of IT infrastructure and the implementation of related knowledge management technologies alone is enough to ensure the global success of organizational knowledge activities (Serenko et al, 2015,1). According to Khatibian et al. (2010), the implementation of knowledge management in the organizations which are mature enough will cause important changes in the organizational process, infrastructure, and culture. The studies have shown that in the field of knowledge management, different maturity models have been introduced (Oliva, 2014, 1057). The knowledge management has been so important that it has been studied by many scholars. Kroger and Johnson (2011), found a positive relationship between knowledge management maturity and organizational efficiency. Arling and Chun (2011) also explored the creation of 
a new type of knowledge in the organization and matured knowledge management in the organization by presenting a conceptual model based on a case study of a defense industry. Ranjbar Jamalabadi et al (2016) in their study evaluated several knowledge management maturity models from different viewpoint, and by introducing some of the knowledge management maturity models, finally compared them to each other.

\section{Valuation Criteria}

Due to the importance of intangible properties, their valuation is an important subject that should receive due consideration (Ghazi noori et al, 2015, 49). Based on this, for the assessment and valuation of the target system needs, and for offering suggestions in order to describe the way of its implementation, and for providing the necessary information for decision-making by the managers, and for assessing the weaknesses and strengths of the present system, and for improving and developing the system at hand (Zahedi, 2012, 325), the identification and specification of system valuation criteria, i.e. assessing the system value by using the three major indices of feasibility, strategic index, and design index (Zahedi, 2012, 338), and their prioritization belong to the effective key factors of proper adopting and implementing of knowledge management system. Therefore, generally, a systematic study should be carried out to ensure the feasibility of the new system prior to the system installation or application in an organization and, the implementation of knowledge management system in each organization should be taken in to account to compromise with the effective conditions and factors of implementation in the organization (Kanapkin et al, 2010), i.e., we ensure that the project will be operating in technical, economic and financial, and staff environments. But, the project attributes determine which factors are more important (Elahi and Hussein Moghadam, 2001: 2). In this regard, Dehghani et al. (2017), also presented a three-layer model, feasibility and effective deployment of knowledge management using the meta-combination method. Hayat Davoudi (2013) also presented a framework for measuring the level of maturity of knowledge management with an emphasis on information technology system factors. Danaeifard, and his colleagues in 2013, They examined ways to enhance evidence-based political, social, administrative, and technical feasibility.

Zahedi (2006) also studied the creation and expansion of administrative information systems management. According to him, for the creation of intelligence systems, we can follow the cycle of biology. Which is being prepared at the planning stage for a strategic general framework of the new information system that meets the needs of the organization and is linked to the overall program of the institution. The criteria used in projects are: feasibility and strategic measures. Also, after planning and analyzing the system in the third stage, it is time for the general prosecution and definition of the conceptual framework of the system to come to light; the projects that have reached this stage are also measured and evaluated in terms of the design index and the valuation Finally, one of them is chosen for detailed design. Also, Zahedi (2012) In his research, he showed that three key indicators were used to measure the value of the system: first, probability index, second strategic or strategic indicator, and third indicator of design. Based on the conceptual model of the research, the criteria of valuation and its indicators are derived from the literature. In this study, 17 variables were included in the feasibility criteria: including technical, economic, legal, operational, timing Human, political, administrative, social, and strategic measures that include components such as productivity, index, management, and design criteria also include components such as maintainability, usability, reusability, reliability, and extendability.

Based on the above materials, the conceptual model of the research will be as the following:

Valuation criteria

1- Feasibility factor

1-1 Technical

1-2- Economical

1-3- legal

1-4- operational

1-5- Timing

1-6-Human Resources 
Fig1. Study model

\section{Research Questions}

1- What are the valuation criteria?

2- What are the indicators of measuring knowledge management maturity level?

3 - What is the ranking importance of each of the valuation criteria?

4- What is the maturity level of knowledge management in the organization?

5- What is the significance of the ranking of each of the indicators for measuring the level of knowledge management maturity?

6- What is the relationship between each of the valuation criteria and the maturity level of knowledge management?

7- What is the validity of the model extracted from the research?

\section{Research methodology}

The present study is a developmental and applied research in terms of its purpose, and is within the framework of descriptive studies. Based on its domain (magnitude) of the statistical sample, it is a case study. Also, for its method of data collecting, it is a survey. Since, in its conceptual framework the relationship between some variables is studied so, it will be a kind of exploratory research. In this study, two questionnaires valuation criteria (Cronbach's $\alpha=0.94$ ), and maturity level of knowledge management (Cronbach's $\alpha=0.93$ ) have been used. The statistical population included 86643 individuals from the staff of administrative organizations of Khuzestan Province; which, by using Cochran's formula, 382 people were selected as the statistical sample. Pearson's correlation coefficient, Friedman's test, and Onesampled T-test were also to answer the research questions.

\section{Research Findings}

Question1: What are the valuation criteria?

Based on the conceptual model of the research, the valuation criteria variable of the study included 17 factors which are namely: technical, economical, legal, operational, timing, human resources, political, administrative, social, strategic, efficiency, index, management, design, maintainability, applicability, Reusability, reliability, extensibility dimensions. 
Table2. Fitness criteria: a for confirmative factor analysis of the valuation criteria

\begin{tabular}{|c|c|c|c|c|c|c|c|c|c|}
\hline Factor & $\mathrm{X}^{2}$ & $\mathrm{df}$ & $\mathrm{Df} / \mathrm{x}^{2}$ & GFI & AGFI & RMSEA & NFI & IFI & CFI \\
\hline Calculated value & 1146 & 560 & 2.04 & 0.84 & 0.97 & 0.07 & 0.88 & 0.83 & 0.91 \\
\hline
\end{tabular}

In this study, the proportionate degree of freedom for the sample of 382 individuals, is greater than 1.96. Hence, it results in the underestimation of GFI and AGFI factors. Also, obtained RMSEA (0.07) is regarded as the desirability of the model fitness. So, the goodness of the fitness factors in the confirmatory factor analysis model of the valuation criteria variable based on the results shown on Table2, show appropriate and desirable fitness of the measuring model; hence, based on this, the model can used for measuring the valuation criteria dimensions.

Question2. What are the measuring criteria of the level of knowledge management maturity?

With respect to the fact that every level of knowledge management maturity is explained by a set of criteria, and by different sets of criteria different models of knowledge management maturity are defined; hence, in this study, a set of common attributes have been paired, so that the set can be representative of the important aspects of every level of knowledge management maturity. Therefore, based on the conceptual model of the study, the variable of the level of knowledge management maturity in this study includes 13 factors which namely are: process, leadership, culture, technology, assessment, staff, knowledge processes, learning and innovation, infrastructure variable, strategy, system and organization.

Table3. Fitness criteria for confirmatory factor analysis of the level of knowledge management maturity

\begin{tabular}{|c|c|c|c|c|c|c|c|c|c|}
\hline \multicolumn{1}{|c|}{ questionnaire } \\
\hline Factor & $\mathrm{X}^{2}$ & df & Df/ $x^{2}$ & GFI & AGFI & RMSEA & NFI & IFI & CFI \\
\hline Calculated value & 1267 & 466 & 2.71 & 0.81 & 0.83 & 0.076 & 0.90 & 0.80 & 0.91 \\
\hline
\end{tabular}

In this study, the proportionate degree of freedom to the sample of 382 individuals is greater than 1.96. Therefore, it leads to the underestimation of GFI, and AGFI factors. Also, obtained RMSEA factor (0.076) is regarded as the desirability of the model fitness. Hence, the goodness of the fitness factors in the confirmatory factor analysis model of the level of knowledge management maturity variable based on the results shown on Table3, show appropriate and desirable fitness of the measuring models; so, based on this, the model can be used for measuring the dimensions of the level of knowledge management maturity.

Question3. What is the relationship between each valuation criteria and the level of knowledge management maturity?

To study the relationship between every valuation criteria and the level of knowledge management maturity, Pearson's Correlation coefficient has been used. The results are shown on Table.4. The results showed that, considering the level of significance $(\mathrm{P}=0.000<0.01)$, there was a direct and significant relationship between feasibility factor and the level of knowledge management maturity with more than $99 \%$ confidence $(\mathrm{r}=0.85)$. Also, considering the level of significance $(\mathrm{P}=0.000<0.01)$, it can be said that with more than $99 \%$. Confidence there is a direct and significant relationship between strategic criteria and the level of knowledge management maturity $(\mathrm{r}=0.86)$. Also, considering the level of significance $(\mathrm{P}=0.000<0.01)$, it can be said that with more than $99 \%$ confidence there is a direct and significant relationship between design factor, and the level of knowledge management maturity ( $\mathrm{r}=0.93)$.

Table4. Study of the relationship between valuation criteria a and the level of knowledge management maturity. 


\begin{tabular}{|c|c|c|c|c|}
\hline Variable & 1 & 2 & 3 & 4 \\
\hline Level of knowledge management maturity & 1 & & & \\
\hline Feasibility factor & ${ }^{* *} 0.85$ & 1 & & \\
\hline Strategic factor & ${ }^{* *} 0.86$ & ${ }^{* *} 0.64$ & 1 & \\
\hline Design factor & ${ }^{* *} 0.93$ & ${ }^{* *} 0.80$ & ${ }^{* *} 0.71$ & 1 \\
\hline
\end{tabular}

Question4. What is the ranking importance of each one of the valuation criteria?

To prioritize and identify the variables that are of the most importance among the valuation criteria Freedman's test was used, which results are shown in table5. Considering the obtained level of significance $(\mathrm{P}=0.000<0.01)$, it can be said with more than $99 \%$ accuracy that zero hypothesis is rejected and the study hypothesis is confirmed. Therefore, it can be concluded that the strata rankings are not equal; the technical factor variable enjoys the highest ranking mean, and the feasibility variable has the lower ranking mean among other variables of the study statistical sample.

Table5. Ranking the valuation criteria variables

\begin{tabular}{|l|l|l|l|l|l|}
\hline Variable & Ranking mean & Priority & K-square & df & p-value \\
\hline Technical & $11 / 09$ & 1 & 402.79 & 16 & 0.000 \\
\hline Economical & $9 / 88$ & 5 & & & \\
\hline Legal & $9 / 98$ & 4 & & & \\
\hline Operational & $9 / 60$ & 8 & & & \\
\hline Timing & $9 / 97$ & 6 & & & \\
\hline Human & $9 / 95$ & 3 & & & \\
\hline Political & $7 / 60$ & 13 & & & \\
\hline Administrative & $7 / 04$ & 15 & & & \\
\hline Social & $10 / 08$ & 2 & & & \\
\hline Efficiency & $9 / 11$ & 9 & & & \\
\hline Index & $7 / 77$ & 12 & & & \\
\hline Management & $8 / 72$ & 10 & & & \\
\hline Maintainability & $6 / 79$ & 16 & & & \\
\hline Applicability & $7 / 26$ & 14 & & & \\
\hline Reusability & $9 / 77$ & 7 & & & \\
\hline Reliability & $9 / 77$ & 7 & & & \\
\hline Extensibility & $8 / 63$ & 11 & & \\
\hline
\end{tabular}

Question5. How much is the level of knowledge management maturity in the organization?

To evaluate this question, mono-sampled T-test was used. Since in this study Lickhert's 5-quedtioned spectrum was used to analyze the questions, the theoretical mean of calculation was considered to be 3.00. Based on the results shown in Table6 the level of significance of the test for 13 variables of the level of knowledge management maturity was calculated to be $\mathrm{P}=0.000$, which is lower than the error level of 0.01. It can be concluded that with more than 99\%. Accuracy there is a significant difference between the obtained mean of the 13 factors of the level of knowledge management maturity variable, and the fixed mean.

Table6. Status of the level of knowledge management maturity variables

\begin{tabular}{|l|l|l|l|l|}
\hline \multirow{2}{*}{ Variable } & \multicolumn{2}{|l|}{ Theoretical mean=3.00 } & DF & P-value \\
\cline { 2 - 5 } & mean & T-value & 382 & .000 \\
\hline Process & 2.9024 & -4.107 & 382 & .000 \\
\hline Leadership & 3.2073 & 7.717 & 382 \\
\hline
\end{tabular}




\begin{tabular}{|l|l|l|l|l|}
\hline Culture & 2.9775 & -.648 & 382 & .518 \\
\hline Technology & 3.0853 & 3.065 & 382 & .002 \\
\hline Assessment & 3.2120 & 6.546 & 382 & .000 \\
\hline Knowledge processes & 3.1880 & 6.400 & 382 & .000 \\
\hline Learning and innovation & 3.1885 & 6.542 & 382 & .000 \\
\hline Results & 3.1972 & 6.539 & 382 & .000 \\
\hline Infrastructure & 3.2022 & 7.823 & 382 & .000 \\
\hline Strategy & 3.0108 & .514 & 382 & .607 \\
\hline System & 3.0175 & .579 & 382 & .563 \\
\hline Organization & 3.0097 & .378 & 382 & .706 \\
\hline staff & 2.9024 & -4.107 & 382 & .000 \\
\hline
\end{tabular}

Question6. What is the importance ranking of each one of the measuring variables of the level of knowledge management maturity?

To prioritize and identify the variables that are of the highest importance among the variables of level of knowledge management maturity, Freedman's test was used, which results are shown in Table7. Considering the obtained level of significance $(\mathrm{P}=0.0001)$ which is less than 0.01 , it can be said with more that $99 \%$ accuracy that the zero hypothesis is rejected and the study hypothesis is confirmed. So, it can be concluded that the strata rankings are not equal; the leadership variable enjoys the highest ranking mean, and the process variable has the lowest ranking mean among other variables of the study statistical sample.

Table7. Rankings of the level of knowledge management maturity variables

\begin{tabular}{|c|c|c|c|c|c|}
\hline Variable & Ranking mean & priority & K-square & $\mathrm{DF}$ & P-value \\
\hline Process & 4.55 & 12 & \multirow{13}{*}{400.530} & \multirow{13}{*}{12} & 0.000 \\
\hline Leadership & 8.28 & 1 & & & \\
\hline Culture & 6.16 & 9 & & & \\
\hline Technology & 7.22 & 7 & & & \\
\hline Assessment & 7.54 & 6 & & & \\
\hline Staff & 7.64 & 5 & & & \\
\hline Knowledge processes & 7.83 & 4 & & & \\
\hline Learning and innovation & 7.84 & 3 & & & \\
\hline results & 7.83 & 4 & & & \\
\hline Infrastructure & 8.07 & 2 & & & \\
\hline Strategy & 5.82 & 10 & & & \\
\hline System & 6.44 & 8 & & & \\
\hline organization & 5.77 & 11 & & & \\
\hline
\end{tabular}

Queation7. What is the validity of the model exported from the study?

Table8. Fitness variables of the modified model $(n=382)$

\begin{tabular}{|l|l|l|l|l|l|l|l|l|l|l|}
\hline Variable & $\mathrm{x}^{2}$ & $\mathrm{df}$ & $\mathrm{df} / \mathrm{x}^{2}$ & GFI & AGFI & NFI & IFI & TLI & CFI & RMSEA \\
\hline Calculated & 1267 & 466 & 2.71 & 0.81 & 0.83 & 0.90 & 0.80 & 0.91 & 0.91 & 0.06 \\
\hline $\begin{array}{l}\text { Acceptable } \\
\text { value }\end{array}$ & & & $<3$ & $0.90>$ & $0.90>$ & $0.90>$ & $0.90>$ & $0.90>$ & $0.90>$ & $0.1<$ \\
\hline Result & Good & Good & Good & Good & Acceptable & Good & good & good & good & good \\
\hline
\end{tabular}

Table7 Shows the obtained value for each one the variables in order to evaluate the goodness of the fitness. With respect to the obtained results, the mode enjoys a desirable validity. 


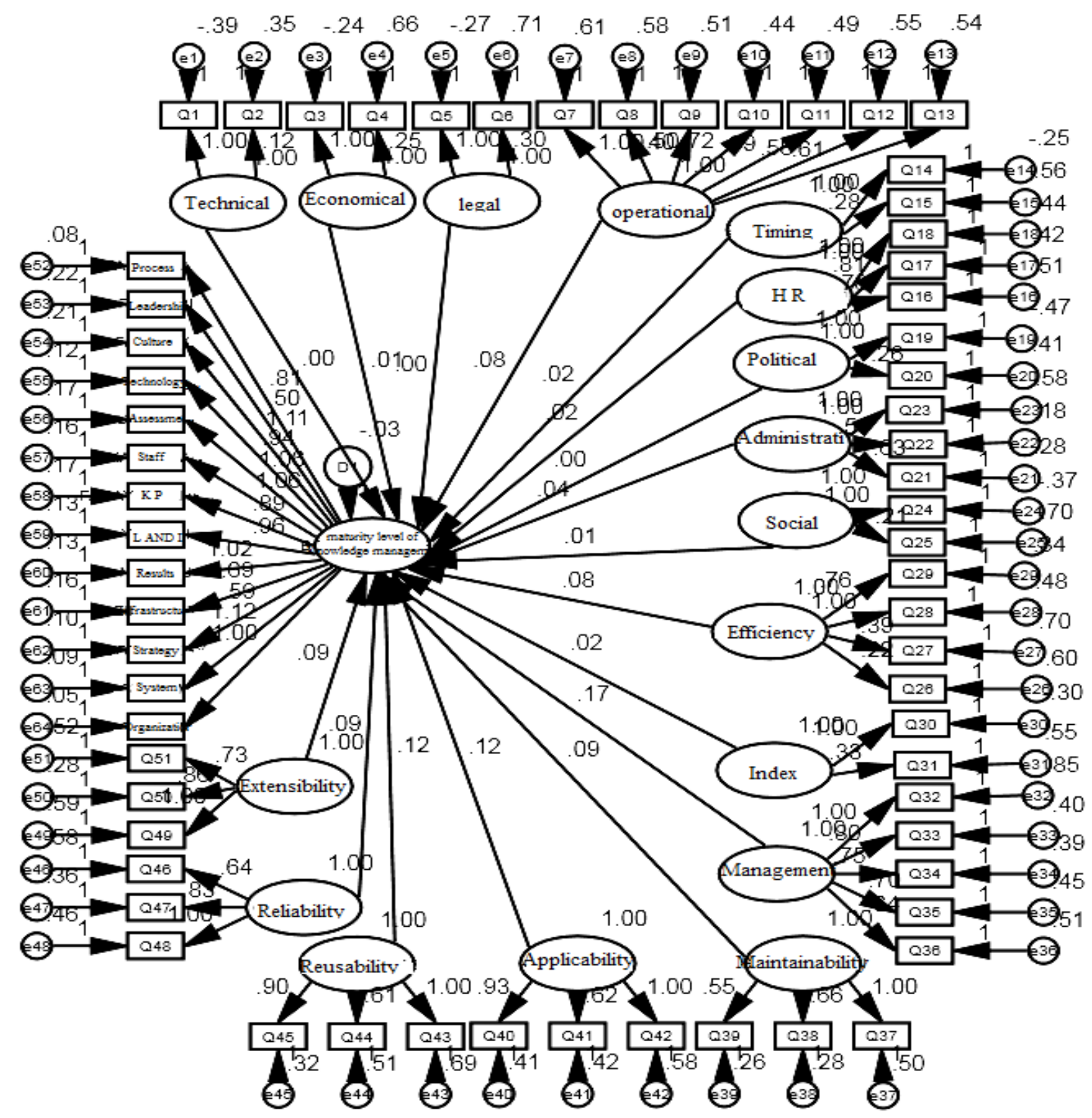

Fig2. Study final model with standardized coefficients

\section{Discussion and Conclusion}

1- According to the results of the first question, the valuation criteria identified in this study include 17 variables that are: technical, economic, legal, operational, timing, human, political, administrative, social, strategic, productivity, index, management, design, maintainability, usability, teusability, reliability, and extensibility. In this regard, we can refer to the studies by Akhawan Kharazi an et al (2016), Ghazi Noori et al (2015),Danaee fard et al (2013), Zahedi (2012), Zahedi (2006), Kruger and Johnson (2010). 
2- According to the results of the second question, the leve of knowledge management maturity indicator in this study, has 13 variables that are: process, leadership, culture, technology, assessment, staff, knowledge processes, learning and innovation, results, infrastructure, strategy, system and organization. In this regard, we can refer to the studies by Mirzaee et al (2017), Akhavan at al (2016), Ranjbar Jamalabadi et al (2016), Serenko et al (2015), Roaming et al (2013), Jiankang et al (2011), Khatibian et al (2010), Hsieh et al (2009), Huang and Sangcho (2005).

3- According to the results of the their question to evaluate the relationship between the valuation criteria and the level of knowledge management maturity Pearson's correlation coefficient was used. The results in the table showed that considering the level of significance $(p=0.000<0.01)$ there is a direct and significant relationship between feasibility criteria, and the level of knowledge management maturity with more than 99\% accuracy. Also, considering the level of significance $(\mathrm{P}=0.000<0.01)$, it can be said that with more than $99 \%$ accuracy there is a direct and significant relationship between the valuation criteria and the level of knowledge management maturity. In this regard, we can refer to the studies by Kruger and Johnson (2010), Arling and Chon (2011), Mandviwalla et al (1998), Ghlich lee and Ebrahimi(2016), Akhavan Kharaziyan et al (2016), Ghazi Nouri et al (2015), Danaee fard et al (2013) and Zahedi (2012).

4- According to the results of the fourth question the variable od the technical index has the highest ranking mean, and the maintenance cabability variable has the lowest ranking mean among there variables of the statistical population of the study. To compare the results of testing this hypothesis with the previous literature, we can refer to the studies by Ghlich lee and Ebrahimi (2016), Akhavan Kharaziyan et al (2016), Ghazi Nouri et al (2015), Danaee far et al (2013), Zahedi (2012), Kruger and Johnson (2010).

5- According to the results of the fifth question, Mono-sampled T-test was used to study the level of knowledge management maturity. With regard to the results of the level of significance for this test for 13 variables of level of knowledge management maturity it was show that the process factor $(M=2 / 90)$ level was more than satisfactory level. Fore leadership factor $(M=3 / 20)$ level was also more than satisfactory level. For culture dimension (2/97) the obtained level was good. For technology dimension (3/08) the obtained level was more than satisfactory. For assessment dimension $(M=3 / 21)$ the obtained level was more than satisfactory. For knowledge processes dimension $(3 / 18)$ the obtained level was more than satisfactory. For learning and innovation dimension $(\mathrm{M}=3 / 18)$ the obtained level was more than satisfactory. For results dimension $(\mathrm{M}=3 / 19)$ the obtained level was good. For infrastructure dimension $(M=3 / 20)$ the obtained level was more than satisfactory. For strategy dimension $(M=3 / 01)$ the obtained level was good. For system dimension (3/01) the obtained level was good. For organization dimension (3/00) the obtained level was good. And, for staff dimension $(M=2 / 90)$ the obtained level was good. In this respect, we can refer to the studies by Wibowo and Waluyo (2015), Jiuling et al (2012), Jiankang et al (2011), Goonesekera and Zyngier (2011), Khatibian et al (2010), and Khadivar and Abbasi (2016).

6- According to the results of the sixth question, considering the obtained level of significance $(\mathrm{P}=0.0001<0.01)$, it can be said that with more than $99 \%$ accuracy the zero hypothesis is rejected and the study hypothesis is confirmed. So, it can be concluded that the strata ranking are not equal. The leadership variable has highest ranking mean, and the process variable has the lowest ranking mean among other variables, of the study statistical population. In this regarded, we can refer to the studies by Hasangholipour et al (2009 Wibowo and Waluyo (2015), Jiuling et al (2012), Jiankang et al (2011), Goonesekera and Zyngier (2011), and Khatibian et al (2010).

\section{Recommendations}

1- In this study, based on the conceptual model, one of the evaluation criteria is the feasibility criteria, and in general, the studies also showed that there is a direct and significant relationship between the feasibility criteria and the maturity level of knowledge management, Therefore, in light of the results obtained in this study, it is suggested that, in the case of a technical component, selective technologies should meet the needs for the creation and implementation of a knowledge management system and be able to provide 
access to the output of the knowledge management system for all employees. Also, regarding the economic component. Given that cost reduction is one of the benefits of knowledge management in government agencies, identifying and predicting constraints and problems associated with the funding required for the creation and implementation of a knowledge management system can also It also helps to reduce the problems with this component. Also, in order to avoid legal and juridical problems in the organization, it is recommended that the data processing system be consistent with the protection of logical data. To this end, it is suggested that legislation and legal frameworks be tailored to the knowledge management in order to provide the system legally and legally. The institution did not create problems and prevented the organization from fulfilling the obligations of the staff.

2- Another criterion of valuation based on the conceptual model of research is strategic measures that include productivity, index, management, and the relationship between the strategic criteria and the level of maturity of knowledge management showed that between this There are two direct and significant relationships, Therefore, in order to improve and improve the strategic criteria, it is suggested that in the case of productivity, the proposed system be considered in terms of increasing the effectiveness of the organization's operations and activities in order to determine how much of the costs that are spent on system building, Do not generate value added. also Creating facilities that utilize advanced knowledge, reduce mid-level management, and use automated controller equipment to save time will also increase productivity in the organization. In the case of indexing factors, it is also suggested that in government agencies, factors such as the quality of service provision, responsibility, and accountability to the citizens should be based. Regarding the improvement and improvement of the third case, the management criterion, it is also suggested that managers' information for planning, decision making, and control is quickly and comprehensible for management through the KM system, to provide an uncertainty concern The main problem for managers is to be reduced.

3- Another criterion of valuation based on the conceptual model of research is design criteria, which showed that there is a direct and significant relationship between design criteria and knowledge management maturity level, Therefore, in order to improve the knowledge management system's design criteria, by enhancing and improving the reliability component, the probability of success of the KM system in organizations has been increased so that the system can, without failure and failure, fulfill the specified tasks with the limits specified in the design and Specific operating conditions apply, and the time to repair and reboot the knowledge management system is also shortened, Regarding The feature of extension is also the need for a proper knowledge structure, and due to the evolution and knowledge developments, this structure has to be flexible enough, because the ability to flexibly adapt and build skills to meet the environmental needs seems very necessary. Therefore, organizations should increase predictability and in this regard, they must devise appropriate strategies to deal with disturbances and uncertainties in order to be able to adjust and grow more, because if the knowledge management system is capable of modulating and adapting With no advancements and changes, it will not go away with increasing user needs.

4- On the variable of the level of knowledge management maturity in general it can be said that we should expand the mechanism of complex ethical data gathering in the organization. The organizations are to record the documents of the organization by using appropriate techniques of transmitting the acquired knowledge and to continuously evaluate their work processes and improve them in order to achieve better performance.

5- The managers can also consider the necessary financial resource for creating a central coordination unit to mange knowledge, to appoint a superior knowledge manager, to form communication technological teams to improve quality, and to design and deploy knowledge networks. Also, the staff of the organization should be evaluated and trained to help the expansion of organizational knowledge.

6- For the culture variable of knowledge management it is suggested to encourage and facilitate knowledge sharing in the organization so that each employee is responsible for learning. In this regard, the organization should establish an open and reliable atmosphere for communications. Also, customer value should be recognized as an important goal of knowledge management in the organization. 
7- It is also suggested that organizations create a specific set of indicators for assessing knowledge management, which can include a set of hard and soft criteria, as well as financial and non-financial indicators. It is also important to encourage the sharing of knowledge and active teamwork, and they should be rewarded.

8- Organizations are recommended to provide technical infrastructure, network and automation equipment in each section. Managers are also suggested to consider written guidelines for creating, distribution, sharing and storage of knowledge in the organization. Also, organizations should have strategic and plans in order to maintain valuable staff in the organization.

\section{References}

-Arling, P.A. (Chun, M.W.S) 2011. Facilitating new knowledge creation and obtaining KM maturity. Journal of Knowledge Management, V.15, P. 231-250.

- Elahi, Sha'ban and Maryam Sadat Hosseini Moghadam, (2003), Study of Feasibility of Establishing EBanking in the Banking System of the Country from the Point of View of Managers and Bankers Experts, First International Conference on Information Technology, and knowledge Tehran, Amirkabir University of Technology.

- Akhavan Kharraziian, M., Salehi Sedghiani, J. and Manafi, M.(2016) Assessment Model for Preparing for the Establishment and Acceptance of Knowledge Management at the Post Office of the Islamic Republic of Iran Information Technology Center, Quarterly Journal of Information Technology Management Studies, Vol. 17, pp. 29-61.

- Hasan Gholipour, Tahmoures, Abedi Jafari, Hasan and Khatibiyan, Neda( 2009) Assessing the level of maturity of knowledge management in organizations through the developed maturity model of knowledge management, Quarterly Journal of Management Sciences, Vol. 4, No. 14, pp. 121-148 .

- Khadivar, A Abbasi, F(2016) Evaluation of knowledge management maturity in the top three hundered top Iranian companies, Journal of Modern Research in Decision Making, Volume 1, Issue 3, pp. 23-41.

- Danaei Fard, Hassan, Azar, Adel and Ebrahimi, Seyyed Abbas;( 2013) Examining the Strategies for Promoting Political, Social, Administrative, and Technical Capabilities of Public Policies of the Country Using Evidence-Based Policy-Making Approach, Journal of Management of Governmental Organizations , Year 1, No. 3, PP.34.

Zakeri, Sh.; (2013) Study of the relationship between Organizational Learning Dimensions and Organizational Maturity Level of Managing Education Staff of Minab City, Quarterly Journal of Research in Humanities, No. 7, pp.185-204.

-Zahedi, Shams al-Sadat(2012) System Analysis and Design, Allameh Tabatabai University, Second Edition, 11th Printing, p.540.

-Zahedi, Shams al-Sadat (2006) Establishment and Expansion of Administrative Information Management Systems, Journal of Management Studies, No. 51.

-Ghlich lee, B and Ebrahimi, Sh., (2016), The feasibility of establishing knowledge management with the approach of the Asian Productivity Organization (APO), Management Outlook Magazine, No.25, pp.95114.

-Ghazi nouri, S. S.; Rajabzadeh Ghatromi, A., and Movadat, P. (2015) Designing a Model for Assessing Technical Knowledge of Markets Techniques, Journal of Technology Development Management, Vol. 3, No. 3, pp. 45-80.

- Moghaddasi, Alireza, 2006, Principles of Designing Information Systems Processes, Management Publication, No. 107-108, pp. 57-60.

-Mimizai, M, Javanmard, H and Hari, M ..S., (2017) Identification of the Patterns of Factors Related to Choosing a Knowledge Management Strategy (Case Study: Three Industrial Organizations), Journal of Strategic Management Research, Year 23, No.65, pp. 153-183.

-Arling, P.A. (Chun, M.W.S) 2011. Facilitating new knowledge creation and obtaining KM maturity. Journal of Knowledge Management, V.15, P. 231-250.

-Choi. B, \& Jong, A. M. (2010). Assessing the Impact of Knowledge Management Strategies Announcements on the Market Value of Firms. Information \& Management, 47 (1), $42-52$. 
-Dehghani, M., Yagwobi, N.M., Moghli, A, and D, Z, 2017, Presentation of Feasibility Study and Establishment of Knowledge Management Effectiveness by Using Combined Method (Integrated Approach), Journal of Management and Management of Public Organizations, Volume 4, Issue 2, Pages 93-107.

-Ehms, K and Langen, M., (2002), 'Holistic Development of Knowledge Management', with KMMM Siemens AG / Corporate Technology Knowledge Management \& Business Transformation; Online Accessible:

http://www.knowledgeboard.com/doclibrary/knowledgeboard/kmmm_article_siemens_2002.pdf,PP: 1-8. -Goonesekera,T and Zyngier,S, 2011, Measuring Knowledge Management Maturity Levels in Organisation's Production Area using Fuzzy Linguistic Variables Proceedings of the 44th Hawaii International Conference on System Sciences, IEEE, PP:1-10

-Hoffer Jefrey A, George Joey F.,valacich Joseph s.(2002) Modern Systems Analysis and Design, Third Edition, prentice Hall, New jercy,USA ,pp.133-162.

- Hayat Davoudi, M. (1392), Knowledge Management Maturity Knowledge Management Framework with Emphasis on Information Technology System Factors (Case Study: Tarbiat Modares UniversityEngineering Faculty), Master's thesis, Tarbiat Modares University.

-Hung, Y. H. \& Chou, S. C. T. (2005, August). On constructing a knowledge management pyramid model. In Information Reuse and Integration, Conf, 2005. IRI-2005 IEEE International Conference on. (pp. 1-6). IEEE.

-HSIEH PJ, LIN B and LIN C (2009) The construction and application of knowledge navigator model $\left(\mathrm{KNM}^{\mathrm{TM}}\right)$ : an evaluation of knowledge management maturity. Expert Systems with Applications 36(2), 4087-4100.

-Jiankang, w, Jiuling, X, Qianwen, L and Kun,L. 2011 ,Knowledge Management Maturity Models:A Systemic Comparison, International Conference on Information Management, Innovation Management and Industrial Engineering.

-Kanapeckiene, L. , Kaklauskas , A. \& Zavadskas , E.K. (2010) Integrated Knowledge Management Model and System for Construction Projects, Engineering Applications of Artificial Intelligence , (pp1200 - 1215).

-Kochikar V P, (2005), 'The Knowledge Management Maturity Model - A Staged Framework for Leveraging Knowledge’, with Principal Knowledge Manager Infosys Technologies Limited, India.

-Kuriakose, K. K., Raj, B., Satya Murty, S. A. V. \& Swaminathan, P. (2011). Knowledge management maturity model: an engineering approach. Journal of Knowledge Management Practice, 12(2): 1-17.

-Khatibian, N., Hasan Gholoipour, T. \& Abedi Jafari, H. (2010). Measurement of knowledge management maturity level with in organizations. Business strategy series,11(1): 1751-5637.

-Kuriakose, K. K., Raj, B., Satya Murty, S. A. V. \& Swaminathan, P. (2011). Knowledge management maturity model: an engineering approach. Journal of Knowledge Management Practice, 12(2): 1-17.

-Kuriakose, K.K., Baldev Raj, Satya Murty, S.A.V. and Swaminathan,P,(2010), Knowledge Management Maturity Models - A Morphological Analysis, Journal of Knowledge Management Practice, Vol. 11, No. 3. . given. ISSN 1705-9232.

-Kruger, C. \& Johnson, R. (2010). Information management as an enabler of knowledge management maturity: A South African perspective. International Journal of Information Management, 30(1): 57-67.

-Oliva, F.L., (2014) Knowledge management barriers, practices and maturity model. Journal of Knowledge Management 18(6), 1053-1074.

-Quinn, M.D., (2005) "People Focused Knowledge Management: How Effective Decision Making Leads to Corporate Success", The Learning Organization, Vol. 12 Iss: 4, pp.389 - 390.

-Ranjbar Jamalabadi, H.R ., Forghani AllahAbadi, M.A and Jalili, J ,2016, Knowledge Management and t Maturity Models (in Organizations), Iranian Journal of Business and Economics, Volume3,Issue2, PP: 49-53.

-Rodrigues, L. L. \& Martis, M. S. (2004). System dynamics of human resource and knowledge management in engineering education. Journal of Knowledge Management Practice, Available in: http://www.tlainc. com/articl77.htm. 
-Ruiming ,Yand Yu Qingan,Y.,(2013), Research on Knowledge Management Maturity Model: Based on the Life Cycle of the Industry, 6th International Conference on Information Management, Innovation Management and Industrial Engineering, PP:259- 262-Robinson, H.S.( Anumba, C.J. Carrillo, P.M. AlGhassani, A.M). 2006, STEPS: a knowledge management maturity roadmap for corporate sustainability . Business Process Management Journal, V.12, P. 793-808.

-Suresh , J.K and Mahesh, K. 2006, Ten Steps to Maturity in Knowledge Management Lessons in economy,First published in Great Britain in 2006, Chandos Publishing, Oxford ,England. pp221.

-Serenko, Alexander, Bontis, Nick and Hull, Emily,(2015), An application of the knowledge management maturity model: the case of credit unions, Knowledge Management Research \& Practice, 115.

-Teah, H. Y., Pee, L. G. \& Kankanhalli, A. (2006). Development and Application of a General Knowledge Management Maturity Model, The Tenth Pacific Asia Conference on Information Systems, 401-416.

-Wibowo, M. A and Rudi Waluyo, R., 2015, Knowledge management maturity in construction companies, The 5th International Conference of Euro Asia Civil Engineering Forum (EACEF-5), Procedia Engineering 125 ,pp: $89-94$. 